\title{
ASSOCIATION OF RESILIENCE WITH QUALITY OF LIFE AND SELF-ESTEEM IN HEALTHCARE WORKERS OF COVID-19 HOSPITAL
}

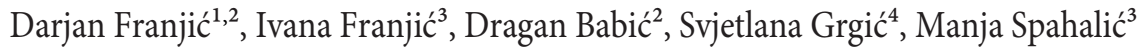 \\ ${ }^{1}$ Department of Oncology, University Clinical Hospital Mostar \\ ${ }^{2}$ Faculty of Health Studies, University of Mostar \\ ${ }^{3}$ Department of Anesthesia, Resuscitation and Intensive Care, University Clinical Hospital Mostar \\ ${ }^{4}$ Department of Infectious Diseases, University Clinical Hospital Mostar \\ 88000 Mostar, Bosnia and Herzegovina
}

Rad je primljen 11.08.2021. Rad je recenziran 27.08.2021. Rad je prihvaćen 05.09.2021.

\begin{abstract}
Introduction: The coronavirus disease 2019 (COVID-19) pandemic has put national health systems under extremely large pressure. Health systems throughout the world demonstrated different levels of preparedness for COVID-19 pandemic. Aim: The aim of the study was to investigate the association of resilience with quality of life and self-esteem in healthcare workers of COVID-19 hospital.

Methods: We performed a cross-sectional study between November 2020 and February 2021 in COVID-19 hospital at the University Clinical Hospital Mostar. A socio-demographic questionnaire specifically designed for this study, a CD-RISC25 scale for assessing resilience, a WHOQOL-BREF questionnaire for assessing quality of life, and a RSES scale for assessing self-esteem were used for collecting data.

Results: A statistically significant higher resilience was in healthcare workers who felt adequately prepared for work in COVID-19 hospital. Resilience, quality of life and self-esteem statistically significantly positively correlated with one another among healthcare workers. A healthcare worker's resilience level was statistically significantly affected by psychological domain of the quality of life, gender, and adequate preparation.

Conclusion: Resilience is positively related to the quality of life and self-esteem in healthcare workers of COVID-19 hospital at the University Clinical Hospital Mostar.
\end{abstract}

Key words: Resilience, quality of life, self-esteem, healthcare workers, COVID-19, hospital

Corresponding author:

Darjan Franjić, MA, PhD candidate

Email: darjanfranjic@gmail.com 


\section{INTRDUCTION}

The global coronavirus disease pandemic has been spreading since December 2019 (1). The coronavirus disease 2019 (COVID-19) pand-emic caused by severe acute respiratory syndr-ome coronavirus 2 (SARS-CoV-2) is still progr-essing and has been recorded in more than 210 countries and territories worldwide (2). Healt-hcare workers have emerged as a vulnerable population group during COVID-19 (3). The COVID-19 pandemic has put national health systems under extremely large pressure. Hea-lth systems throughout the world demonst-rated different levels of preparedness for COVID-19 pandemic. The corona-crisis tested the resilience of health professionals (4). Resilience represents the individual's ability to deal with adversities as challenges. It has been shown to reduce the impact of traumatic events such as coping with a pandemic (5). Also, it represents growing, developing and getting better for the individual (6).

A lack of resilience in the workplace and increased work-based stress levels may also imp-act the overall quality of life negatively impa-cting not just on the individual but the wider family group and community (7). Resilience varies from person to person and depends on several factors, such as personality or interpersonal and social backgrounds (8).

The cumulative effects of stress and profes-sional challenges can lead to harmful impacts for healthcare workers including burnout and poorer physical and mental health, as well as a lower level of self-esteem (9). Burnout and psychological distress among healthcare wor-kers severely affect personal health and welln-ess, patient safety and quality of care, and he-alth care system costs (10). Working under ext-reme pressures, prolonged shifts due to insuf-ficient staffing and incoming sickness of colle-agues, insufficient availability of personal pro-tective equipment, fear of infection and transmission to family members, and the daily need to take morally burdensome decisions, resulted in a profound sense of danger, moral injury and mental health problems (11-13). Some people who have to contend with significant challenges, moral or traumatic, experience a degree of posttraumatic growth, a term used to describe a bolstering of resilience, self-esteem, outlook, and values after exposure to highly challenging situations (1). Self-esteem has been defined as the evaluation of oneself and that is one of the key psychological constructs $(14,15)$. Whether someone develops a psychological injury or experiences psychological growth is likely to be influenced by the way that they are supported before, during, and after a chall-enging situation (11). The literature suggests that resilient individuals are better equipped to deal with the stressors that result from a constantly demanding work environment, such as health services (16). Hence, supporting the mental wellbeing and resilience of frontline healthcare workers is imperative to ensure global recovery from the COVID-19 pandemic (17).

The aim of this study was to investigate the association of resilience with quality of life and selfesteem in healthcare workers of COVID-19 hospital.

\section{METHODS}

We performed a cross-sectional study between November 2020 and February 2021 at the Clinic of Infectious Disease of the University Clinical Hospital (UCH) Mostar that has been transformed into a hospital facility for clinical management of COVID-19. Data were collected through drop off/pick up method of questionnaire distribution.

Healthcare workers over the age of 18 years assigned to work in a COVID-19 facility are included in this study. Healthcare workers with a history or a family history of mental illness, experiencing a major negative event in the 3 months prior to testing, such as personal health problems (i.e. went to doctor or stayed in hospital), serious illness or death of a family member, divorce or separation, or involvement in a legal dispute were excluded of this study. Participants were informed about the study before starting any procedures. All participants volunteered for this study and provided informed consent. A sample size of 100 subjects was required for test strength of $\beta=0.80$. In order to raise the quality and strength of the research, the total sample size in this paper was 130 patients. The number of valid questionnaires retrieved was 116 (response rate $=93.5$ $\%)$. The study was conducted in accordance with the Declaration of Helsinki (as revised in 2013). Prior to the conduct of the research, the written consent of the Ethics and Human Rights Commission of UCH Mostar was obtained. The research was conducted in accordance with ethical principles and human rights in the research. The interviewing for study was anonymous.

\section{QUESTIONNAIRES}

We used the socio-demographic questionnaire personally designed, made for this research, to obtain data on respondents such as: gender, age, education, marital status, smoking habits, occupation, adequate preparation for work with COVID-19 patients, and confidence to complete task. Resilience was measured 

workers of covid-19 hospital. Zdravstveni glasnik. 2021;7(2):13-22.

using the Connor Davidson Resilience Scale 25. This is a 25-item test that yields a score between 0 and 100 . Higher scores indicate higher resilience. The survey asks respondents to rate their agreement, using a 5point Likert scale from "completely disagree" to "completely agree" (18). Cronbach alpha coefficient for this questionnaire in our research was 0.87 . The World Health Organization Quality of Life-BREF questionnaire was used to assess quality of life. Perceptions of quality of life in each of the four domains of quality of life (physical health -7 particles, mental health - 6 particles, social relations - 3 particles, and the environment - 8 particles) are scored, with the scale positively directed. Two particles refer to the assessment of overall quality of life satisfaction. The questionnaire consists of 26 particles, and each question is scored on a Likert scale from 1 (worst) to 5 (best) (19). Cronbach alpha coefficient in this research is 0.88 . The Rosenberg Self-Esteem Scale was used for evaluating individual self-esteem among health care workers. The Rosenberg Self-Esteem Scale is a 10 -item scale that measures global self-worth by measuring both positive and negative feelings about the self. The scale is believed to be uni-dimensional. All items are answered using a 5-point Likert scale format ranging from strongly agree to strongly disagree (20). In this study, Cronbach's alpha coefficient was 0.79 . All the above instruments are standardized, validated and approved by the author.

\section{STATISTICAL ANALYSIS}

Data analysis was performed using Statistical Package for Social Science statistical software version 26.0 (IBM Corp., Armonk, NY). The collected data were processed by the descriptive statistics method. For count data, frequencies and percentages were used. Arithmetic mean and standard deviation were used to represent the mean and scatter measure. Hi square test was used to compare group differences of categorical variables. Differences in resilience scores between medical staff with different demographic characteristics were assessed for significance using the independent-samples t-test and one-way ANOVA. The Tukey HSD (Honestly Significant Difference) test is used after a significant $F$ ratio is found via an analysis of variance test. Pearson correlation was used to explore the correlation of resilience with the domains of quality of life and self-esteem. Standard multiple regression analysis was conducted to identify the predictors of psychological resilience in the study population. The probability level in all tests of $p<$ 0.05 is taken as statistically significant. 


\section{RESULTS}

The mean age of participants was 31.52

$(\mathrm{SD}=8.05)$ years, with minimum and maximum ages of 20 and 59 . The mean resilience total score was $77.16(\mathrm{SD}=11.505)$. According to the sociodemographic characteristics, there was a statistically significantly higher number of women, aged 31-40, with secondary education. The sample was statistically significantly mostly composed of nurses (Table 1).

Table 1. Sociodemographic characteristics

\begin{tabular}{|c|c|c|c|c|}
\hline & $n$ & $\%$ & $x^{2}$ & $p$ \\
\hline Gender & & & 15.207 & $<0.001$ \\
\hline Male & 37 & 31.9 & & \\
\hline Female & 79 & 68.1 & & \\
\hline Age & & & 35.552 & $<0.001$ \\
\hline$<25$ & 29 & 25.0 & & \\
\hline $26-30$ & 29 & 25.0 & & \\
\hline $31-40$ & 40 & 34.5 & & \\
\hline $41-50$ & 15 & 12.9 & & \\
\hline $50>$ & 3 & 2.6 & & \\
\hline Education & & & 38.966 & $<0.001$ \\
\hline High school & 53 & 45.7 & & \\
\hline Bachelor's degree & 25 & 21.6 & & \\
\hline Master’s degree & 32 & 27.6 & & \\
\hline Doctorate & 6 & 5.2 & & \\
\hline Marital status & & & 0.000 & 1.000 \\
\hline Unmarried & 58 & 50.0 & & \\
\hline Married & 58 & 50.0 & & \\
\hline Smoking status & & & 1.241 & 0.265 \\
\hline Yes & 52 & 44.8 & & \\
\hline No & 64 & 57.2 & & \\
\hline Ocupation & & & 93.517 & $<0.001$ \\
\hline Doctor & 23 & 19.8 & & \\
\hline Nurse & 73 & 62.9 & & \\
\hline Support staff & 7 & 6.0 & & \\
\hline 0thers $^{\mathrm{a}}$ & 13 & 11.2 & & \\
\hline Preparation & & & 3.448 & 0.063 \\
\hline Yes & 48 & 41.4 & & \\
\hline No & 68 & 58.6 & & \\
\hline Confidence & & & 93.241 & $<0.001$ \\
\hline Yes & 110 & 94.8 & & \\
\hline No & 6 & 5.2 & & \\
\hline
\end{tabular}

$\mathrm{n}$ - Number of patients; $\chi^{2}$ - Chi-square test; ${ }^{\mathrm{a}}$ Radiological engineers and physiotherapists 
A statistically significant higher resilience was in female healthcare workers and in those healthcare workers who felt adequately prepared for work in COVID-19 hospital (Table 2).

Table 2. Evaluation of resilience in terms of sociodemographic characteristics

\begin{tabular}{|c|c|c|c|c|}
\hline Characteristic & $\overline{\bar{X}}$ & SD & Test & $p$ \\
\hline Gender & & & $t=2.661$ & $0.009^{*}$ \\
\hline Male & 73.11 & 12.58 & & \\
\hline Female & 79.05 & 10.51 & & \\
\hline Age & & & $F=0.682$ & 0.606 \\
\hline$<25$ & 76.90 & 12.74 & & \\
\hline $26-30$ & 78.59 & 10.86 & & \\
\hline $31-40$ & 78.05 & 11.46 & & \\
\hline $41-50$ & 73.40 & 11.14 & & \\
\hline $50<$ & 72.67 & 8.32 & & \\
\hline Education & & & $F=1.031$ & 0.382 \\
\hline High school & 78.00 & 11.74 & & \\
\hline Bachelor's degree & 78.04 & 11.17 & & \\
\hline Master's degree & 76.47 & 10.27 & & \\
\hline Doctorate & 69.67 & 16.53 & & \\
\hline Marriage status & & & $\mathrm{t}=0.887$ & 0.703 \\
\hline Unmarried & 76.21 & 11.01 & & \\
\hline Married & 78.10 & 11.99 & & \\
\hline Smoking status & & & $\mathrm{t}=0.081$ & 0.059 \\
\hline Ves & 77.06 & 12.42 & & \\
\hline No & 77.23 & 10.80 & & \\
\hline Occupation & & & $\mathrm{F}=2.138$ & 0.099 \\
\hline Doctor & 73.87 & 11.81 & & \\
\hline Nurses & 78.56 & 11.39 & & \\
\hline Support staff & 81.86 & 16.30 & & \\
\hline 0thers ${ }^{\mathrm{d}}$ & 72.54 & 5.69 & & \\
\hline Preparation & & & $t=3.763$ & $<0.001$ \\
\hline Yes & 81.69 & 10.91 & & \\
\hline No & 73.96 & 10.88 & & \\
\hline Confidence & & & $t=0.908$ & 0.366 \\
\hline Yes & 77.38 & 11.50 & & \\
\hline No & 73.00 & 11.78 & & \\
\hline
\end{tabular}

${ }^{*} \mathrm{p}<0.05 ;{ }^{a}$ Radiological engineers and physiotherapists; $\overline{\mathrm{X}}=$ Arithmetic mean; SD = Standard Deviation; $\mathrm{F}$ One-way ANOVA; $\mathrm{t}$ - Independent sample t-test 
Resilience statistically significantly positively correlated with quality of life and self-esteem. The strongest statistically significant positive correlation was found between resilience and psychological health (Table 3).

Table 3. Correlation of resilience with quality of life and self-esteem

\begin{tabular}{lc} 
& \multicolumn{1}{c}{ Resilience } \\
\cline { 2 - 3 } Overall quality of life & $\mathrm{r}$ \\
Physical health & $0.389^{* * *}$ \\
Psychological health & $0.227^{* *}$ \\
Social relationship & $0.534^{* *}$ \\
Environment & $0.406^{* *}$ \\
Self-esteem & $0.359^{* *}$ \\
\hline
\end{tabular}

$\mathrm{r}=$ Pearson's correlation; ${ }^{*} \mathrm{p}<0.05 ;{ }^{* *} \mathrm{p}<0.001$

Of all the domains of quality of life, the domain of psychological health has largely significantly independently contributed to the level of resilience. The contribution was positive. The results demonstrated that a healthcare worker's resilience level was statistically significantly affected by adequate preparation. Other domains of quality of life, selfesteem and gender did not make a statistically significant independent contribution to the level of resilience. The regression analysis model as a whole was statistically significant and explained $39.0 \%$ of the variance (Table 4).

Table 4. Predictive contributions of selected factors to the level of resilience

\begin{tabular}{lccc}
\hline Resilience & $\beta$ & $\mathrm{t}$ & $\mathrm{p}$ \\
\hline Physical health & -0.076 & -0.770 & 0.443 \\
Psychological health & 0.281 & 2.187 & 0.031 \\
Social relationships & 0.117 & 1.142 & 0.256 \\
Environmental & 0.051 & 0.497 & 0.620 \\
Self-esteem & 0.183 & 1.929 & 0.056 \\
Gender & 0.143 & 1.811 & 0.073 \\
Preparation & 0.225 & 2.868 & 0.005 \\
\hline
\end{tabular}

$\mathrm{R}^{2}=0.390 ;$ Model: $\mathrm{F}(108 ; 7)=9.861 ; \mathrm{p}<0.05 ; \beta$ - Standardized beta coefficient; $\mathrm{t}$ - T-test 


\section{DISCUSSION}

Numerous studies have been conducted in relation to the association between resilience, mental health risks and other factors among frontline healthcare workers during COVID-19 pandemic (21, 22). Results of our study show that resilience positively correlated with quality of life and self-esteem among healthcare workers. Our results show that resilience was positively affected by adequate preparation for work in COVID-19 hospital. We found that female healthcare workers had a statistically significantly higher level of resilience in comparison with males. Our results show that psychological health and preparedness were statistically significantly contributed to the level of resilience. Results of a study conducted by Lin et al. show that healthcare workers who are prepared for work in COVID-19 hospital show significant higher resilience level (23). Some authors stated that psychological resilience levels of healthcare wor-kers in their later years were found to be higher (24). Recent studies state that experienced staff has presented a significantly higher level of resilience during COVID-19 outbreak (25). Our results show that no significant difference was recorded among the respondents in relation to their age nor their experience. Results of a study conducted by Huang et al. show that the resilience level of the medical staff in the radiology departments during the outbreak of COVID-19 was generally low (26). Several studies have been conducted to investigate the association between selected factors and resilience and to evaluate the potential effect of resilience on psychic symptoms among physicians $(27,28)$. Their results show that resilience level of the physicians was generally low. Our results show that physicians had a lower level of resilience compared to nurses. Bozdağ and Ergün stated that doctors constitute the group with the lowest levels of psychological resilience among healthcare workers (24). Zwack and Schweitzer found phy-sical activities reduced tension and cultural pur-suits helped put professional stressors into perspe-ctive. In the mentioned study, the sample consisted exclusively of experienced doctors (29).

In our study far more respondents were nurses than doctors. In line with our results, analysis of 120 frontline nurses working in the emergency department in North India during COVID-19 pan-demic showed a moderate to high level of resilience (30). Recent systematic reviews has shown that imp-lementing the approach for increasing psychological resilience will also protect the mental health of individuals against other risks that may develop (31). Our results are consistent with the aforementioned study. Some studies show that higher level of resilience was protective variable for mental health (32). This is in good agreement with our results. Social relationship positively correlated with resil-ience and that healthcare workers showed signific-antly lower resilience, when compared to the non-health care professionals (33, 34). This study has not confirmed previous research on social relations and resilience. Some studies found that a higher level of resilience was strongly associated with selfefficacy, higher purpose of life and emotional support (35). Babić et al. state that numerous facts related to the association between resilience and various types of diseases (36). Franjić and co-workers state that people with a higher level of recovery ability cope with stressful situations more easily (37). Consistent with our results, some authors state that people with breast cancer who have a higher level of resilience have a better quality of life (38). A study conducted by Gao et al. show that resilience and selfesteem mediated most of the effect of negative life events on positive social adjustment (39). According to Pollock et al., when selecting interventions aimed at supporting frontline healthcare workers mental health, organizational, social, personal, and psychological factors may all be important (40). Robertson et al. stated that positive influences on resilience included social resources, physical activity, and outside interests. Our results have a number of similarities with aforementioned findings (41).

In relation to the methodology, unlike our study, some studies were of prospective (8) or comparative (13) design. Further, Zwack and Schweitzer (29) conducted semistructured interviews. However, in some studies a webbased Google form survey was sent on the internet through any social media of selected participants $(30,35)$.

Different types of questionnaires have been used in previous studies to measure the level of resilience in healthcare workers during COVID-19 pandemic. Some authors measured resilience in healthcare workers with 14items resilience scale (34), brief resilience scale (24) and 10item Connor-Davidson Resilience Scale (27).

There are some limitations in the present study that should be taken into consideration when inter-preting the findings. We cannot exclude the possib-ility that factors in the survey environment, such as other people present, may have influenced subject's responses. Further, the crosssectional design can-not offer a precise explanation of the causal mech-anisms between two variables. Longitudinal studies will be necessary to further confirm our results and to assess changes in resilience among healthcare workers during a pandemic. This study is largely based on quantitative methods. Quali-tative methods should be considered to explore the meaning of the relationship among resilience, domains of the quality of life, and selfesteem. Also, other variables, such as the intensity of psychotic symptoms, were not evaluated. We recommend 
Franjić D, Franjić I, Babić D, Grgić S, Spahalić M. Association of resilience with quality of life and self-esteem in healthcare workers of covid-19 hospital. Zdravstveni glasnik. 2021;7(2):13-22.

that future studies additionally apply the focus group method, which will provide more subjective explanations of the patient's attitudes. In addition to the above limitations, the obtained results and the constant relevance and significance of the topic give significant meaning and value to the study. The results of this study may provide guidance in establishing resilienceenhancing interventions in healthcare workers during COVID-19 pandemic, especially in those healthcare workers who directly care for patients with COVID-19 disease.

\section{CONCLUSIONS}

Resilience is positively related to the quality of life and self-esteem in healthcare workers of COVID-19 hospital at the University Clinical Hospital Mostar. The preparedness of healthcare workers to work at Covid-19 hospital plays a statistically significant role in their level of resilience. In line with the results of this study, it seems to be important to expand the interventions for increasing resilience with the aim of reducing psychological symptoms among healthcare workers during the COVID-19 pandemic.

\section{REFERENCES}

1.Brooks S, Amlôt R, Rubin GJ, Greenberg N. Psychological resilience and post-traumatic growth in disaster-exposed organizations: overview of the literature. BMJ Military Health, 2020;166:52-6. https://doi.org/10.1136/jramc-2017-000876.

2.Arapović J, Skočibušić S. The first two months of the COVID-19 pandemic in Bosnia and Herzegovina: Single-center experience. Bosn J Basic Med Sci. 2020;20(3):396-400.

https://doi.org/10.17305/bjbms.2020.4838

3.Smith C. The structural vulnerability of healthcare workers during COVID-19: observations on the social context of risk and the equitable distribution of resources. Soc Sci Med. 2020;258:113119.

4. Wahlster S, Sharma M, Lewis AK, Patel PV, Hartog C, Jannotta G, et al. The COVID-19 pandemic's impact on critical care resources and providers: A Global Survey. Chest. 2021;159(2):619-633. https://doi.org/10.1016/j.chest.2020.09.070

5.Lee JS, Ahn YS, Jeong KS, Chae JH, Choi KS. Resilience buffers the impact of traumatic events on the development of PTSD symptoms in firefighters. J Affect Disord. 2014;162:128-133.

https://doi/10.1016/j.jad.2014.02.031

6.Jakovljević M. Empathy, sense of coherence and resilience: bridging personal, public and global mental health and conceptual synthesis. Psychiatr Danub. 2018;30:380-384. https://doi.org/10.24869/psyd.2018.380

7.McAllister M, McKinnon J. The importance of teaching and learning resilience in the health disciplines: a critical review of the literature. Nurse Educ Today. 2009;29: 371-9. https://doi.org/10.1016/j.nedt.2008.10.011

8. Chen S, Bonanno GA. Psychological adjustment during the global outbreak of COVID-19: A resilience perspective. Psychol Trauma. 2020;12:51-54. https://doi.org/10.1037/tra0000685

9.Foster K, Roche M, Delgado C, Cuzzillo C, Giandinoto JA, Furness T. Resilience and mental health nursing: An integrative review of international literature. Int J Ment Health Nurs.

2019;28(1):71-85. https://doi.org/10.1111/inm.12548

10. West CP, Dyrbye LN, Shanafelt TD. Physician burnout: contributors, consequences and solutions. J Intern Med. 2018;283(6):516-529. https://doi.org/10.1111/joim.12752

11. Greenberg N, Docherty M, Gnanapragasam S, Wessely S. Managing mental health challenges faced by healthcare workers during covid-19 pandemic. BMJ. 2020;26:368. https://doi.org/10.1136/bmj.m1211

12. Santarone K, McKenney M, Elkbuli A. Preserving mental health and resilience in frontline healthcare workers during COVID-19. Am J Emerg Med. 2020;38:15301531.

https://doi.org/10.1016/j.ajem.2020.04.030

13. Liang Y, Wu K, Zhou Y, Huang X, Zhou Y, Liu Z. Mental health in frontline medical workers during the 2019 novel Coronavirus disease epidemic in China: A comparison with the general population. Int J Environ Res Public Health. 2020;17:6550. https://doi.org/10.3390/ijerph17186550

14. Jelić M. New cognitions in researching the selfesteem: the construct of the self-esteem security. In: Zrinščak S, editor. The social researches Zagreb. The Institute of the Social Sciences Ivo Pilar; 2012.p. 443-463.

15. Grolnick WS, Beiswenger KL. Facilitating children's self-esteem: the role of parents and teachers. In: Kernis MH, editor. Self-Esteem Issues and Answers: A Source book of Current Perspectives. Taylor \& Francis Group; 2006. p. 230-237.

16. Jackson D, Firtko A, Edenborough M. Personal resilience as a strategy for surviving and thriving in the face of workplace adversity: a literature review. J Adv Nurs. 2007;60(1):1-9. https://doi.org/10.1111/j.13652648.2007.04412.x

17. Huang J, Liu F, Teng Z, Chen J, Zhao J, Wang $\mathrm{X}$, et al. Care for the psychological status of frontline medical staff fighting against Coronavirus Disease 2019 (COVID-19). Clin Infect Dis. 2020;71(12):3268-3269. https://doi.org/ 10.1093/cid/ciaa385

18. Connor KM, Davidson JR. Development of a 
Franjić D, Franjić I, Babić D, Grgić S, Spahalić M. Association of resilience with quality of life and self-esteem in healthcare workers of covid-19 hospital. Zdravstveni glasnik. 2021;7(2):13-22.

new resilience scale: the Connor-Davidson Resilience Scale (CD-RISC). Depress Anxiety. 2003;18(2):76-82. https://doi.org/10.1002/da.10113

19. Skevington SM, Lotfy M, O'Connell KA, WHOQOL Group. The World Health Organization's WHOQOLBREF quality of life assessment: psychometric properties and results of the international field trial. A report from the WHOQOL group. Qual Life Res. 2004;13:299-310.

20. Rosenberg M. Society and the adolescent self-image. Princeton University Press; 1965.

21. Albott CS, Wozniak JR, McGlinch BP, Wall $\mathrm{MH}$, Gold BS, Vinogradov S. Battle buddies: rapid deployment of a psychological resilience intervention for health care workers during the COVID-19 pandemic. Anesth Analg. 2020;131(1):43-54. https://doi.org/10.1213/ANE.0000000000004912

22. El-Hage W, Hingray C, Lemogne C, Yrondi A, Brunault P, Bienvenu T, et al. Health professionals facing the coronavirus disease 2019 (COVID-19) pandemic: What are the mental health risks?. Encephale. 2020;46 Suppl 3:73-80.

23. Lin J, Ren YH, Gan HJ, Chen Y, Huang YF, You XM. Factors associated with resilience among nonlocal medical workers sent to Wuhan, China during the COVID-19 outbreak. BMC Psychiatry. 2020;20:417. https://doi.org/ 10.1186/s12888-020-02821-8

24. Bozdağ F, Ergün N. Psychological resilience of healthcare professionals during COVID-19 pandemic. Psychol Rep. 2020. Advance online publication. https://doi.org/ 10.1177/0033294120965477 25. Cai W, Lian B, Song X, Hou T, Deng G, Li H. A cross-sectional study on mental health among health care workers during the outbreak of Corona Virus Disease. Asian J Psychiatr. 2019;51:102111.

https://doi.org/10.1016/j.ajp.2020.102111

26. Huang L, Wang Y, Liu J, Ye P, Cheng B, Xu $\mathrm{H}$, et al. Factors associated with resilience among medical staff in radiology departments during the outbreak of 2019 Novel Coronavirus Disease (COVID19): A cross-sectional study. Med Sci Monit. 2019;26:e925669. https://doi.org/10.12659/MSM.925669 27. Mosheva M, Hertz-Palmor N, Dorman Ilan S, Matalon N, Pessach IM, Afek A, et al. Anxiety, pandemic-related stress and resilience among physicians during the COVID-19 pandemic. Depress Anxiety. 2020;37(10):965-971.

28. Arslan HN, Karabekiroglu A, Terzi O, Dundar C. The effects of the COVID-19 outbreak on physicians' psychological resilience levels. J Postgrad Med. 2021;133(2):1-8. https://doi.org/10.1080/00325481.2021.1874166

29. Zwack J, Schweitzer J. If every fifth physician is affected by burnout, what about the other four? Resilience strategies of experienced physicians. Acad Med. 2013;88(3):382-9. https://doi.org/10.1097/ACM.0b013e318281696b

30. Jose S, Dhandapani M, Cyriac MC. Burnout and resilience among frontline nurses during COVID-19 pandemic: a cross-sectional study in the emergency department of a Tertiary Care Center, North India. Indian J Crit Care Med. 2020;24(11):1081-1088. https://doi.org/10.5005/jp-journals-10071-23667

31. Bahar A, Koçak HS, Bağlama SS, Çuhadar D. Can psychological resilience protect the mental health of healthcare professionals during the COVID-19 pandemic period? Dubai Med J. 2020;3:133-139. https://doi.org/10.1159/000510264

32. Luceño-Moreno L, Talavera-Velasco B, GarcíaAlbuerne Y, Martín-García J. Symptoms of posttraumatic stress, anxiety, depression, levels of resilience and burnout in Spanish health personnel during the COVID-19 pandemic. Int J of Environ Res. 2020;17(15):5514. https://doi.org/10.3390/ijerph17155514

33. Taku K. Relationships among perceived psychological growth, resilience and burnout in physicians. Pers Individ. 2014;59:120-123.

34. Lisi L, Ciaffi J, Bruni A, Mancarella L, Brusi V, Gramegna $P$, et al. Levels and factors associated with resilience in Italian healthcare professionals during the COVID-19 pandemic: a web-based survey. Behav Sci. 2020;10(12):183.

35. Pietrzak RH, Feingold JH, Feder A, Charney DS, Peccoralo L, Southwick SM, et al. Psychological resilience in frontline health care workers during the acute phase of the COVID-19 pandemic in New York City. J Clin Psychiatry. 2020;82(1):137-49. https://doi.org/10.4088/JCP.20113749

36. Babić R, Babić M, Rastović P, Curlin M, Šimić J, Mandić K, et al. Resilience in health and illness. Psychiatr Danub. 2020;32 Suppl 2:226-232.

37. Franjić D, Marijanović I, Babić D. Karcinom debelog crijeva i rezilijencija. Zdravstveni glasnik [Internet]. 2019 [pristupljeno 29.09.2021.];5(2):66-74. https://doi.org/10.47960/2303-89616.2019.10.66

38. Boškailo E, Franjić D, Jurić I, Kiseljaković E, Marijanović I, Babić D. Resilience and quality of life of patients with breast cancer. Psychiatr Danub. 2021 SpringSummer;33(Suppl 4):572-579.

39. Gao F, Yao Y, Yao C, Xiong Y, Ma H, Liu H. The mediating role of resilience and self-esteem between negative life events and positive social adjustment among left-behind adolescents in China: a cross-sectional study. BMC Psychiatry. 2019;19(1):239. https:/doi.org/10.1186/s12888-019-2219-z

40. Pollock A, Campbell P, Cheyne J, Cowie J, 

workers of covid-19 hospital. Zdravstveni glasnik. 2021;7(2):13-22.

Davis B, McCallum J. Interventions to support the resilience and mental health of frontline health and social care professionals during and after a disease outbreak, epidemic or pandemic: a mixed methods systematic review. Cochrane Database Syst Rev. 2020;11:CD013779.

https://doi.org/10.1002/14651858.CD013779

41. Robertson HD, Elliott AM, Burton C, Iversen L, Murchie P, Porteous T, et al. Resilience of primary healthcare professionals: a systematic review. $\mathrm{Br} \mathrm{J}$ Gen Pract.

2020;66(647):423-33.

https://doi.org/10.3399/bjgp16X685261 